\title{
Estudos sazonais de aspectos limnólogicos de um fragmento florestal inundado na Planície do Araguaia, Tocantins, Brasil.
}

\author{
Hiulha de Jesus SILVA ${ }^{[1]}$, Marcus Vinícius Moreira BARBOSA ${ }^{[1]}$ e Paula Benevides de MORAIS ${ }^{[2]}$ \\ ${ }^{[1]}$ Universidade Federal do Tocantins, Campus Palmas. Laboratório de Microbiologia e Biotecnologia Ambiental. Avenida NS 15, 109 Norte - \\ Plano Diretor Norte, 77001-090. Palmas-TO, Brasil. Email: hiulhajs@gmail.com; marcus0588@ hotmail.com \\ ${ }^{[2]}$ Professora do programa de Pós-Graduação Doutorado em Biodiversidade e Biotecnologia da Amazônia Legal (BIONORTE). Laboratório de \\ Microbiologia e Biotecnologia Ambiental. Avenida NS 15, 109 Norte - Plano Diretor Norte, 77001-090. Palmas-TO, Brasil. E-mail: \\ moraispb@uft.edu.br
}

\section{INFORMAÇÕES} RESUMO

Recebido em: 07/09/2015

Aceito em: 28/11/2015

Publicado em: 23/12/2015

Document Object Identifier

10.18067/jbfs.v2i4.76

Termos de indexação:

Pulso de inundação

Fatores físico-químicos

Ipuca

*Autor para correspondência hiulhajs@gmail.com químicos no decorrer do tempo amostral.
Ipucas são ecossistemas de fragmentos florestais naturais, ocorrendo particularmente na planície do Araguaia. Apresenta grande influência dos pulsos de inundação que ocorrem no período chuvoso, pois permanecem inundadas durante este período e como ambientes terrestres no período seco. $\mathrm{O}$ estudo objetivou avaliar a variação temporal de fatores limnológicos em uma Ipuca, no município de Lagoa da Confusão, Tocantins, através de coletas mensais entre Dezembro/2014 e Agosto/2015. As variáveis mensuradas foram: transparência através do disco Secchi, turbidez (NTU), oxigênio dissolvido $(\mathrm{mg} / \mathrm{L})$, temperatura $\left({ }^{\circ} \mathrm{C}\right)$, potencial hidrogeniônico - $\mathrm{pH}$, sólidos totais dissolvidos $(\mathrm{ppm})$, condutividade elétrica $(\mu \mathrm{S} / \mathrm{cm})$, amônia $-\mathrm{NH}_{3}(\mathrm{mg} / \mathrm{L})$, nitrito $-\mathrm{NO}_{2}$ $(\mathrm{mg} / \mathrm{L})$, nitrato $-\mathrm{NO}_{3}(\mathrm{mg} / \mathrm{L})$, ortofosfato $-\mathrm{P}(\mathrm{mg} / \mathrm{L})$, clorofila- $\alpha(\mu \mathrm{g} / \mathrm{L})$ e profundidade da lamina d'água $(\mathrm{cm})$. A transparência total da água e os baixos valores de turbidez demonstram a importância da precipitação nestes parâmetros, assim como a estrutura florestal da Ipuca suporta os valores encontrados. A temperatura da água nas Ipucas foi influenciada pelas estações do ano. O oxigênio dissolvido esteve diretamente relacionado a clorofila- $\alpha$. A concentração dos nutrientes analisados apresentou grandes oscilações, provavelmente devido à rápida incorporação destes pelas comunidades aquáticas. Contudo, foi observada uma homogeneização dos parâmetros físico-

\section{Seasonal studies of limnological aspects of a wetland forest fragment in the Araguaia Plains, Tocantins, Brazil}

\begin{abstract}
Ipucas are ecosystems of natural forest fragments, occurring particularly in the Araguaia plain. It has great influence of flood pulses that occur during the rainy season because they remain flooded during this period and as terrestrial environments in the dry season. The study aimed to evaluate the temporal variation of limnological factors in a Ipuca in the district of the Lagoa da Confusão, Tocantins, through monthly collections between December/2014 and August/2015. The variables measured were: transparency by Secchi disk, turbidity (NTU), dissolved oxygen $(\mathrm{mg} / \mathrm{L})$, temperature $\left({ }^{\circ} \mathrm{C}\right)$, hydrogen potential - $\mathrm{pH}$, total dissolved solids (ppm), electrical conductivity $(\mu \mathrm{S} / \mathrm{cm})$ ammonia $-\mathrm{NH}_{3}(\mathrm{mg} / \mathrm{L})$ nitrite $-\mathrm{NO}_{2}(\mathrm{mg} / \mathrm{L})$ nitrate $-\mathrm{NO}_{3}(\mathrm{mg} / \mathrm{L})$, orthophosphate $-\mathrm{P}(\mathrm{mg} / \mathrm{L})$ $\alpha$-chlorophyll $(\mathrm{mg} / \mathrm{L})$ and depth of the water blade $(\mathrm{cm})$. The total water transparency and low turbidity values demonstrate the importance of the precipitation of these parameters, as well as the structure of the forest Ipuca supports the values found. The water temperature of Ipucas was influenced by the seasons. The dissolved oxygen was directly related to chlorophyll- $\alpha$. The concentration of nutrients analyzed showed big swings, probably due to the rapid incorporation of the aquatic communities. However, a homogenization of physical and chemical parameters during the sampling time was observed.
\end{abstract}

Index terms: flood pulse; Physical and chemical factors; Ipuca.

Copyright: ( ) 2015 JBFS all rights. This is an open-access article distributed under the terms of the Creative Commons Attribution License, which permits unrestricted use, distribution, and reproduction in any medium, provided the original author and source are credited.

Financiamento: Coordenação de Aperfeiçoamento de Pessoal do Ensino Superior (CAPES) - Uma bolsa de Iniciação Científica e outra de Doutorado

Conflito de interesse: Os autores declaram que não há conflito de interesse.

Como referir esse documento (ABNT):

SILVA, H. J.; BARBOSA, M. V. M.; MORAIS, P. B Estudos sazonais de aspectos limnólogicos de um fragemnto florestal inundado na Planície do Araguaia, Tocantins, Brasil. Journal of Bioenergy and Food Science, Macapá, v.2, n.4, p.239-248, out./dez., 2015. http://dx.doi.org/10.18067/jbfs.v2i4.76 


\section{INTRODUÇÃO}

As Ipucas, endêmicas da região do Médio Araguaia, nos estados de Tocantins e Mato Grosso, ocorrem como ilhas de florestas, são ecossistemas de fragmentos florestais temporariamente inundáveis caracterizados por uma região de superfície mais rebaixada em relação à planície [1, 2]. Diferentes dos campos que as circundam, as Ipucas possuem características próprias de florestas densas, comparadas a ambientes inundáveis da Amazônia [1]. De acordo com Haidar et al [3] as espécies arbóreas mais comuns são: Calophyllum brasiliense (landi), Vochysia divergens (canjerana), e espécies típicas amazônicas como Licania parvifolia, Panopsis rubescens e Sclerolobium froesii.

O clima da Região Hidrográfica do Tocantins-Araguaia se caracteriza como tropical, com a presença de dois períodos sazonais bem definidos: um chuvoso, que se estende de outubro a abril, com mais de $90 \%$ da precipitação, e outro seco, de maio a setembro [4]. A alternância entre cheia e seca favorece o desenvolvimento de pulsos de inundação, o que beneficia a distribuição de padrões únicos de vegetação, como no caso das Ipucas [5]. Os pulsos de inundação, que ocorrem anualmente, alternam fases aquática e terrestre nestes fragmentos, com importantes implicações ecológicas à biota associada [6]. No caso das Ipucas, a sazonalidade vai influenciar na deposição e mineralização da matéria orgânica, elemento importante na ciclagem de nutrientes deste ecossistema, uma vez que, durante a seca, quando as árvores perdem mais folhas, o solo fica recoberto por uma camada espessa de material seco e em decomposição (serapilheira). Ao ponto que a estação chuvosa favorece o acúmulo de matéria orgânica, já que a atividade microbiana fica limitada pela inundação [1].

Guimarães et al. [7] afirmam que o nível da água é fator determinante nos processos ecológicos de ambientes aquáticos, pois são responsáveis por mudanças nos padrões de ciclagem de nutrientes e caraterísticas limnológicas, tornando-os estreitamente relacionadas ao pulso de inundação e precipitação, pois eles determinam a variação no nível e área de superfície da lâmina d'água. Associado ao ciclo sazonal tem-se a variação espaço-temporal. Juntos a dinâmica desses fatores são responsáveis pela distribuição de calor, nutrientes, íons e gases dissolvidos na coluna de água [8].
Os ecossistemas lênticos, mesmo isolados de outros ambientes aquáticos, são dependentes das interações com o ecossistema terrestre e podendo apresentar mudanças em respostas a atividades antrópicas que acontecem em seu entorno[9, 10]. A fim de se conhecer mais acerca da dinâmica nas Ipucas e considerando que os padrões limnológicos podem ser utilizados para ações de conservação e monitoramento destes ecossistemas, o estudo teve como objetivo avaliar a variação temporal de parâmetros físico-químicos da água e a influência exercida pelo pulso de inundação nestas variáveis numa Ipuca na região do município de Lagoa da Confusão-TO.

\section{MATERIAL E MÉTODOS}

O estudo foi conduzido em uma Ipuca localizada na fazenda Lago Verde no Município de Lagoa da Confusão, Estado do Tocantins. Por meio de visita de campo, foram escolhidos três pontos amostrais para monitoramento físico-químico da água. O primeiro ponto foi selecionado próximo à borda da Ipuca, nas coordenadas 0639838 e 8798168 , zona 22. O segundo ponto de monitoramento fica mais ao centro da Ipuca, nas coordenadas 0639795 e 8798238 , zona 22. O terceiro ponto situa-se no centro da Ipuca, que permanece sempre inundada, mesmo na época de estiagem, na coordenada 0639757 e 8798276 , zona 22. Sendo estes locais amostrais separados por aproximadamente 50 metros (Figura 1).

As coletas foram realizadas mensalmente em um período de nove meses, em função do regime de chuvas (dezembro, janeiro, fevereiro, março, abril, maio, junho, julho e agosto), período em que a Ipuca encontra-se completamente encharcada e começa a esvaziar. A metodologia para avaliação dos parâmetros limnológicos foi a mesma para todos os pontos.

Os parâmetros avaliados foram: transparência através do disco Secchi, turbidez (NTU), oxigênio dissolvido $(\mathrm{mg} / \mathrm{l})$, temperatura $\left({ }^{\circ} \mathrm{C}\right)$, potencial hidrogeniônico - $\mathrm{pH}$, sólidos totais dissolvidos $(\mathrm{ppm})$, condutividade elétrica $(\mu \mathrm{S} / \mathrm{cm})$, amônia $\mathrm{NH}_{3}(\mathrm{mg} / \mathrm{l})$, nitrito $-\mathrm{NO}_{2}(\mathrm{mg} / \mathrm{l})$, nitrato $-\mathrm{NO}_{3}$ $(\mathrm{mg} / \mathrm{l})$, ortofosfato - P $(\mathrm{mg} / \mathrm{l})$, clorofila- $\alpha(\mu \mathrm{g} / \mathrm{L})$ e profundidade da lamina d'água $(\mathrm{cm})$. 
Figura 1. Descrição da área de estudo.

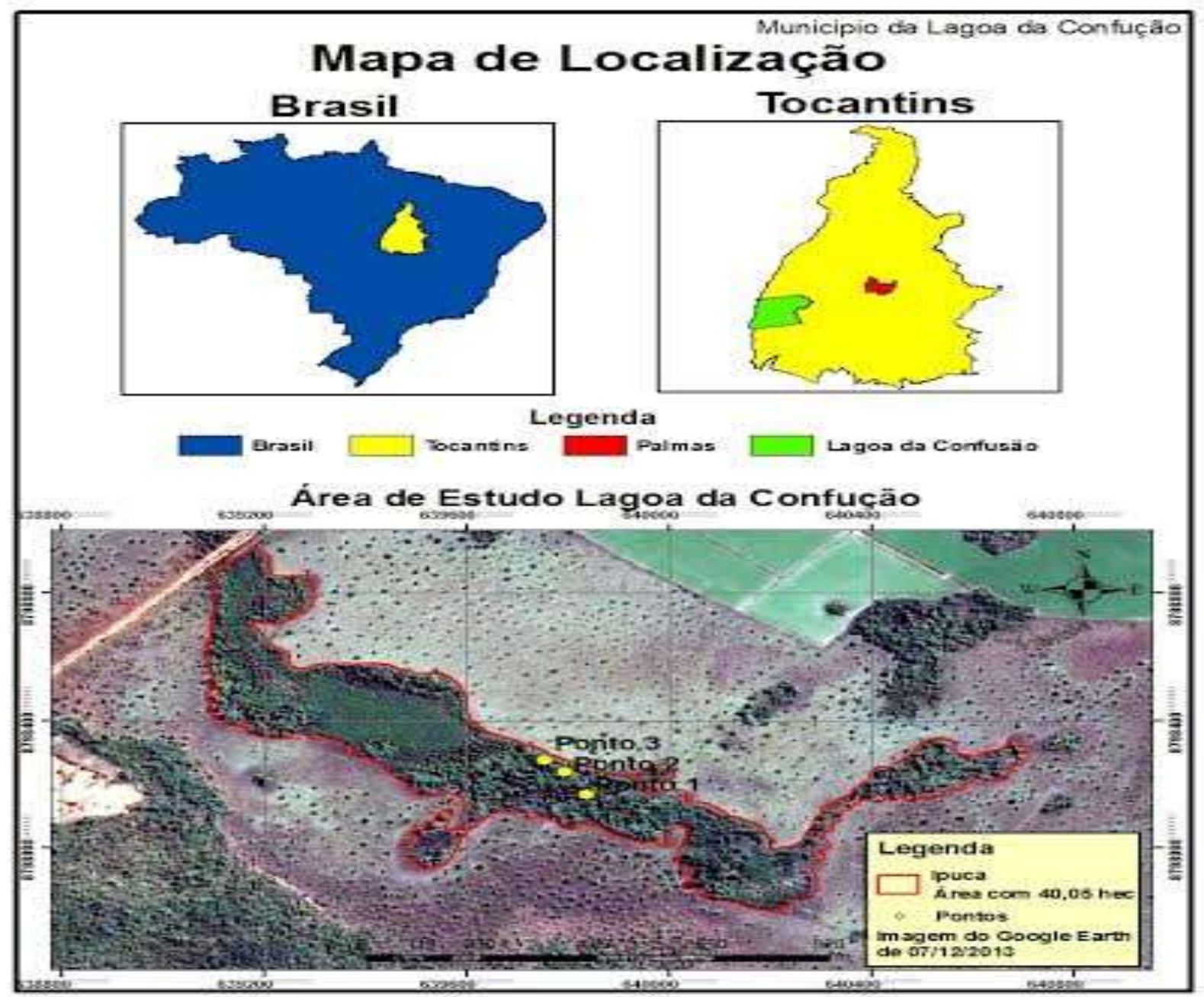

Para se chegar ao ponto de coleta, foi utilizado um barco a remo. Em primeiro momento foram analisadas as variáveis: temperatura $\left({ }^{\circ} \mathrm{C}\right)$, oxigênio dissolvido $(\mathrm{mg} / \mathrm{l})$, potencial hidrogeniônico - $\mathrm{pH}$, sólidos totais dissolvidos $(\mathrm{ppm})$ e condutividade elétrica $(\mu \mathrm{S} / \mathrm{cm})$ realizados diretamente no ambiente mediante utilização de soda multiparâmetros - horiba - modelo U- 22XD. Em seguida verificou-se a transparência da água no lacais de monitoramento através da visibilidade do disco Secchi, e com o auxílio de uma trena mediuse a profundidade que o disco afundou para se ter a altura da coluna d'água.

Para realização de analises de amônia $\mathrm{NH}_{3}(\mathrm{mg} / \mathrm{L})$ nitrito $-\mathrm{NO}_{2}(\mathrm{mg} / \mathrm{L})$, nitrato $-\mathrm{NO}_{3}$ $(\mathrm{mg} / \mathrm{L})$, ortofosfato - $\mathrm{P}(\mathrm{mg} / \mathrm{l})$, clorofila- $a$ e turbidez (NTU) foram coletadas amostras da água mediante utilização de uma garrafa de Van Dorn, armazenadas em caixa de isopor com gelo, e conduzidas ao laboratório, onde se procede com as análises dos parâmetros de acordo com a metodologia descrita no "Standard Methods" APHA [11].
Já os dados mensais de precipitação foram obtidos através do site do Instituto Nacional de Meteorologia [12] considerando a estação meteorológica mais próxima à cidade de Lagoa da Confusão, no caso a do município de Marianópolis do Tocantins.

\section{RESULTADOS E DISCUSSÃO}

A princípio foi feito uma relação entre os dados de precipitação, obtidos pelo INMET [12] com a profundidade dos locais amostrais nos períodos amostrados (Figura 2). Através disso, observou-se que, como esperado, a profundidade dos locais amostrais acompanhou a precipitação, ou seja, quanto maior a quantidade de chuva maior foi a profundidade dos locais amostrais. Do mesmo modo, à medida que a quantidade de chuva decresceu, o nível de água dos locais amostrais foi diminuindo, ao ponto que, em agosto, com zero de precipitação o Ponto 1 apresentava-se completamente sem água. 
Figura 2. Variação da profundida $(\mathrm{cm})$ do nível de água nos três locais no decorrer dos períodos amostrais em função da precipitação (mm) pluviométrica mensal.

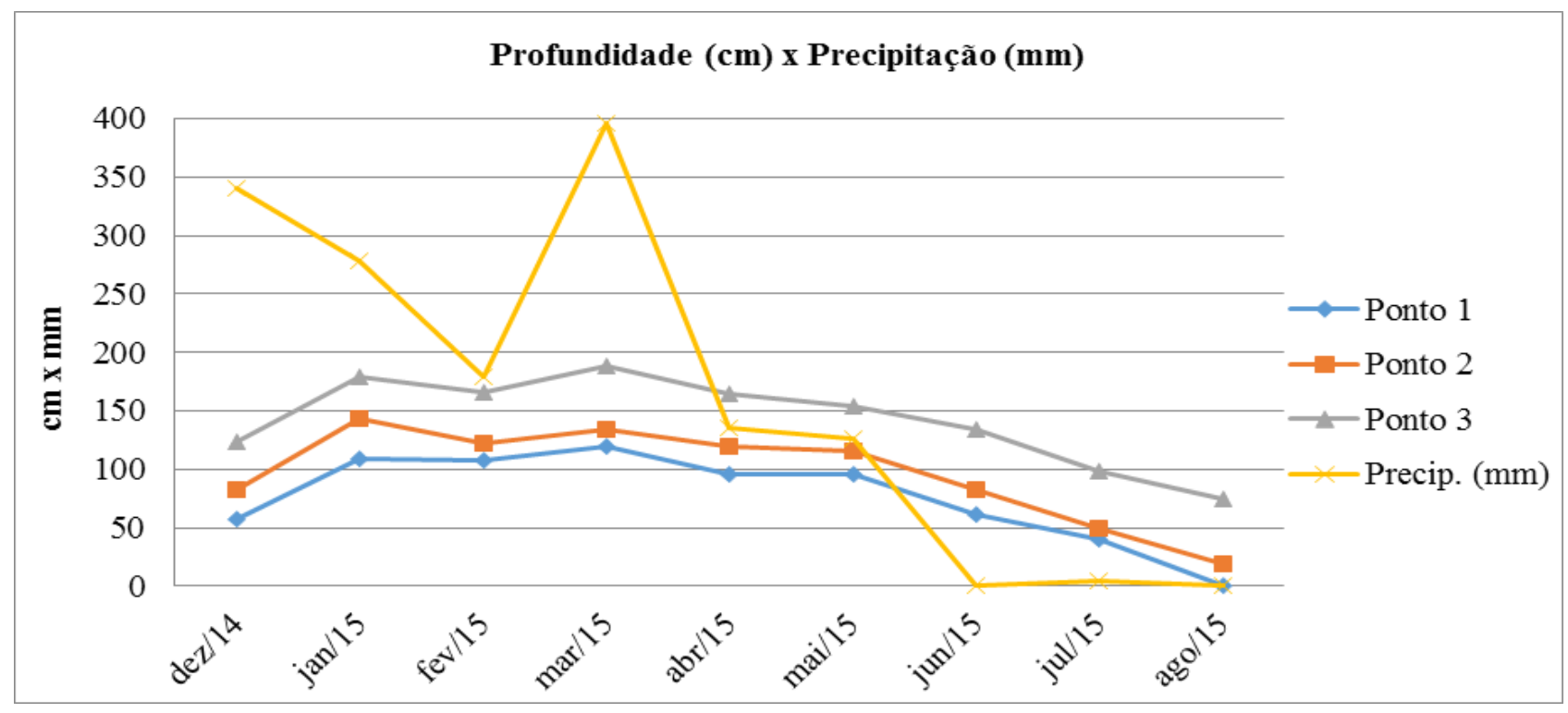

Os resultados de transparência, obtidos pelo disco Secchi, apresentaram-se constantes e com transparência total em todos locais amostrados (pontos 1, 2 e 3), independentes do período e do regime pluviométrico. Isso ocorreu provavelmente devido à existência de uma vegetação densa, pois a copa das árvores pode limitar o revolvimento de material em suspenção pela chuva. Além disso, a presença de capim nas áreas adjacentes a Ipuca serve como filtro impedindo que sedimentos sejam carreados para dentro do ecossistema, favorecendo também uma menor turbidez da água [10]. A transparência tem a característica de permitir a penetração de luz solar na lamina d'água, favorecendo a fotossíntese. Assim, é afetada por materiais dissolvidos e em suspenção, sendo inversamente proporcional a presença de materiais orgânicos e inorgânicos que dificultam a entrada da luz solar no ambiente aquático [9]. Os dados aqui obtidos foram diferentes dos encontrados por Ferreira et al. [13] em três sub-bacias hidrográficas na região central do Rio Grande do Sul, onde a transparência no disco Secchi mostrou-se variável durante todo o período de coleta.

Os parâmetros físicos obtidos neste trabalho estão apresentados na Figura 3. Segundo Sperling [13] a turbidez em ambientes aquáticos é conferida por sólidos em suspenção de origem natural (argila, silte, partículas de rochas e algas) ou antrópica (dejetos domésticos e industriais), e podem reduzir a penetração de luz prejudicando a fotossíntese. Considerando a turbidez, observa-se que houve baixa variação nos Pontos 1 e 2 no decorrer do período amostral. Isso ocorreu, provavelmente, devido à densa vegetação existente nestes locais. Já no Ponto 3, onde não há cobertura vegetal, pois não seca no decorrer do ano, observa-se que os valores de turbidez acompanharam os dados de precipitação, pois a chuva revolve os materiais em suspenção da água (Figura 3). Por outro lado, os baixos valores podem indicar um maior grau de passagem de luz através da lâmina d'água, favorecendo assim, o processo de fotossíntese.

Os valores de sólidos totais dissolvidos mostraram o mesmo padrão de variação que a condutividade elétrica (Figura 3). Esta representa a capacidade da água em transportar corrente elétrica, estando diretamente relacionada a íons dissolvidos na água, indicando características do solo em questão. Os principais minerais responsáveis pelos valores de condutividade são: cálcio, magnésio, potássio, sódio, carbonatos, carbonetos, sulfatos e cloretos [9, 10]. Alguns destes minerais, como o cálcio e magnésio, estão presentes no solo de Ipucas [1], explicando em partes os valores de condutividade nos locais amostrais.

A temperatura da água apresentou um aumento inicial, seguido por um decréscimo no decorrer dos períodos amostrais, tanto no Ponto 1, 2 e 3 (Figura 3). Tal aumento inicial na temperatura da água pode ser explicado pela pouca efetividade dos ventos nos períodos próximos a março, pois segundo Breunig et al. [14] quanto menor a quantidade de vento agindo na coluna d'água, maior 
será a sua temperatura. Assim, a partir de março a temperatura da água começa a diminuir, coincidindo com o início do período de estiagem, onde os ventos encontram-se mais intensos, o que promovendo tal declínio.

A água na Ipuca estudada apresentou-se com pH neutro com uma pequena tendência a ácido principalmente no início e fim do período amostral (Figura 3). A variação do $\mathrm{pH}$ entre os três pontos amostrais foi mínima. Valores semelhantes de $\mathrm{pH}$ também foram obtidos por Perreira e Bleich [9] em uma lagoa na bacia Araguaia-Tocantins durante o período chuvoso. As diminuições nos valores de $\mathrm{pH}$ podem estar associadas a decomposição da matéria orgânica que eleva o teor de gás carbônico livre no meio aquático. Contrário à isto temos a atividade fotossintética, representada pela clorofica $\alpha$, que aumenta o valor do $\mathrm{pH}$, através do consumo de gás carbônico presente no meio, com conseguinte elevação na disponibilidade de oxigênio [9]. Martins et al. [1] citam que os solos nas Ipucas são extremamente ácidos, com presença de carbono orgânico em superfície. Assim, provavelmente devido a isto, e pela decomposição da matéria orgânica, o pH da água da Ipuca se apresentou ligeiramente ácido. A baixa variação na amplitude do índice de $\mathrm{pH}$ pode indicar um equilíbrio entre taxa de decomposição da matéria orgânica e a produção de oxigênio dissolvido, representado principalmente pela fotossíntese.

Figura 3. Variação dos parâmetros físicos: (I) turbidez, (II) condutividade elétrica, (III) sólidos totais dissolvidos, (IV) temperatura e (V) pH nos três locais no decorrer dos períodos amostrais.
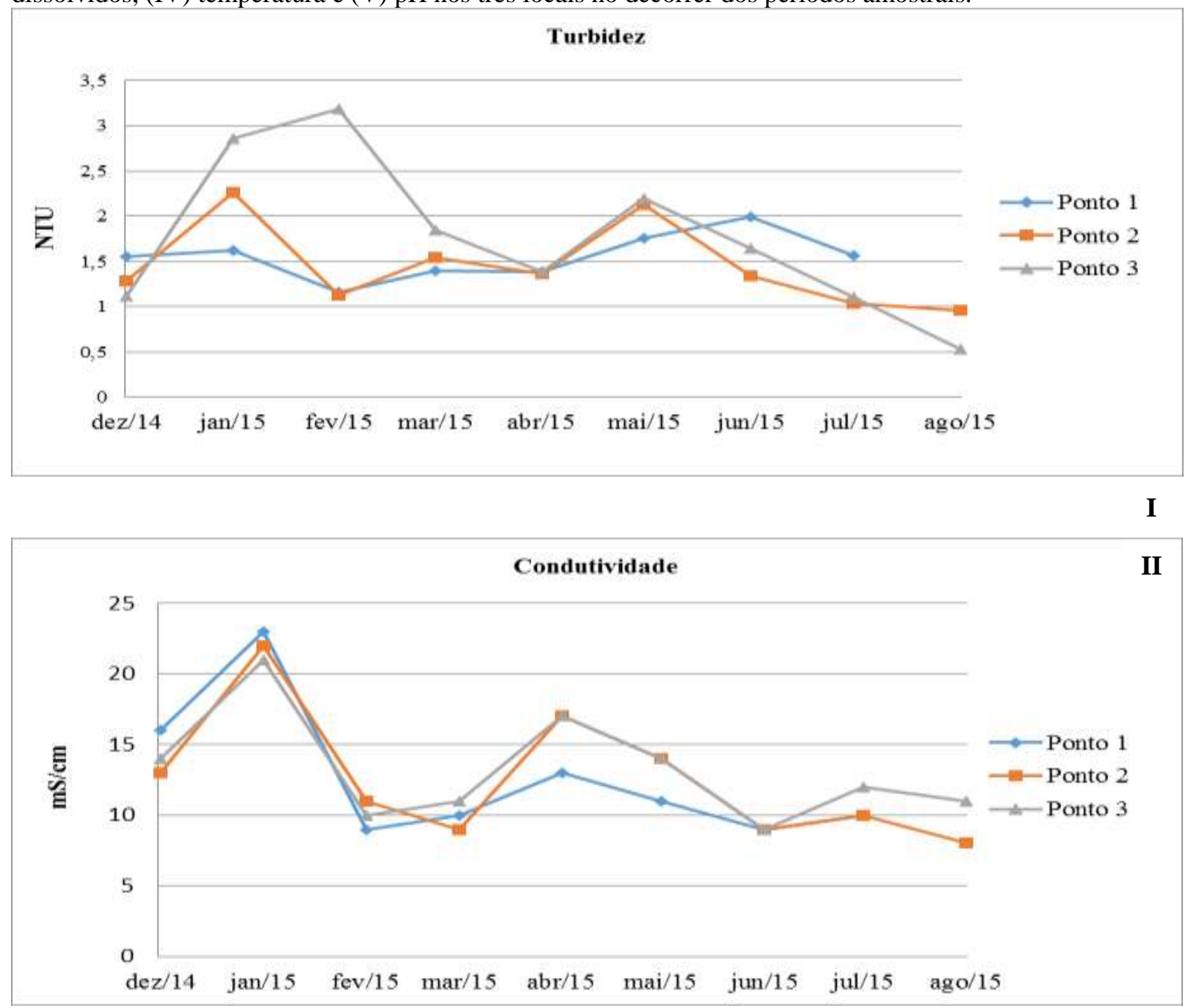

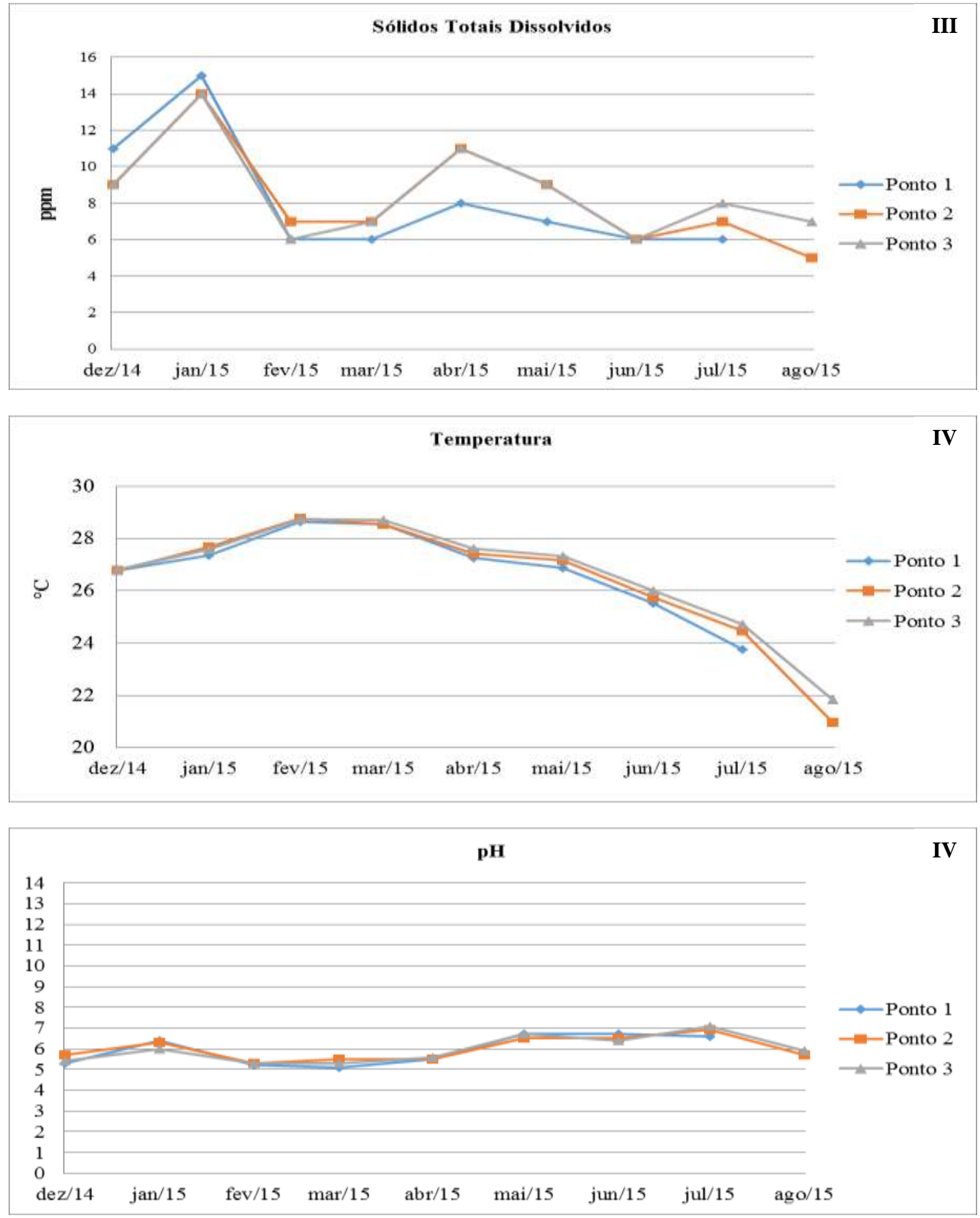

Os valores de oxigênio dissolvido e a clorofila- $\alpha$ estão apresentados na Figura 4. Sabe-se que o aumento na temperatura eleva a taxa de reações físicas, químicas e biológicas e diminui a solubilidade de gases, como exemplo, o oxigênio dissolvido [14]. De acordo com Esteves [15], a solubilidade do oxigênio na água depende da temperatura e pressão, acrescentando que ambientes aquáticos tropicais possuem menor concentração de oxigênio dissolvido em relação aos lagos de regiões temperada, devido às elevadas temperaturas. $\mathrm{O}$ oxigênio dissolvido mede o grau de arejamento da água, sendo aderido ao ecossistema aquático pela produção de organismos fotossintéticos e pela dissolução do oxigênio atmosférico, porém, perdas na quantidade de oxigênio nestes ambientes estão 
relacionadas à decomposição da matéria orgânica (oxidação), respiração de organismos aquáticos e oxidação de íons metálicos, como ferro e manganês $[14,16]$.

Os teores de oxigênio dissolvido presentes na água da Ipuca variaram temporalmente, mas não entre os locais amostrados (Figura 4). A partir de abril a concentração de oxigênio dissolvido aumenta, mostrando-se inversamente proporcional a temperatura da água que a partir deste mês diminuiu gradativamente. Isso coincide com as afirmações de Sperling [13] e Esteves [15], em que o aumento da temperatura diminui a solubilidade dos gases.
A clorofila- $\alpha$, que é indicativo da atividade fotossintética e apresenta relação positiva com oxigênio dissolvido na água, variou entre os três locais amostrais (Figura 4). Segundo Esteves [15] em regiões tropicais os fatores que interferem neste parâmetro é a quantidade de chuva e consequentemente as variações nos níveis da lâmina d'água, que foram instáveis no decorrer do período amostral, refletindo assim, nos valores obtidos de clorofila- $\alpha$.

Figura 4: Variação da concentração de oxigênio dissolvido (I) e os valores de clorofila- $\alpha$ (II) nos três locais amostrais no decorrer do período amostral.

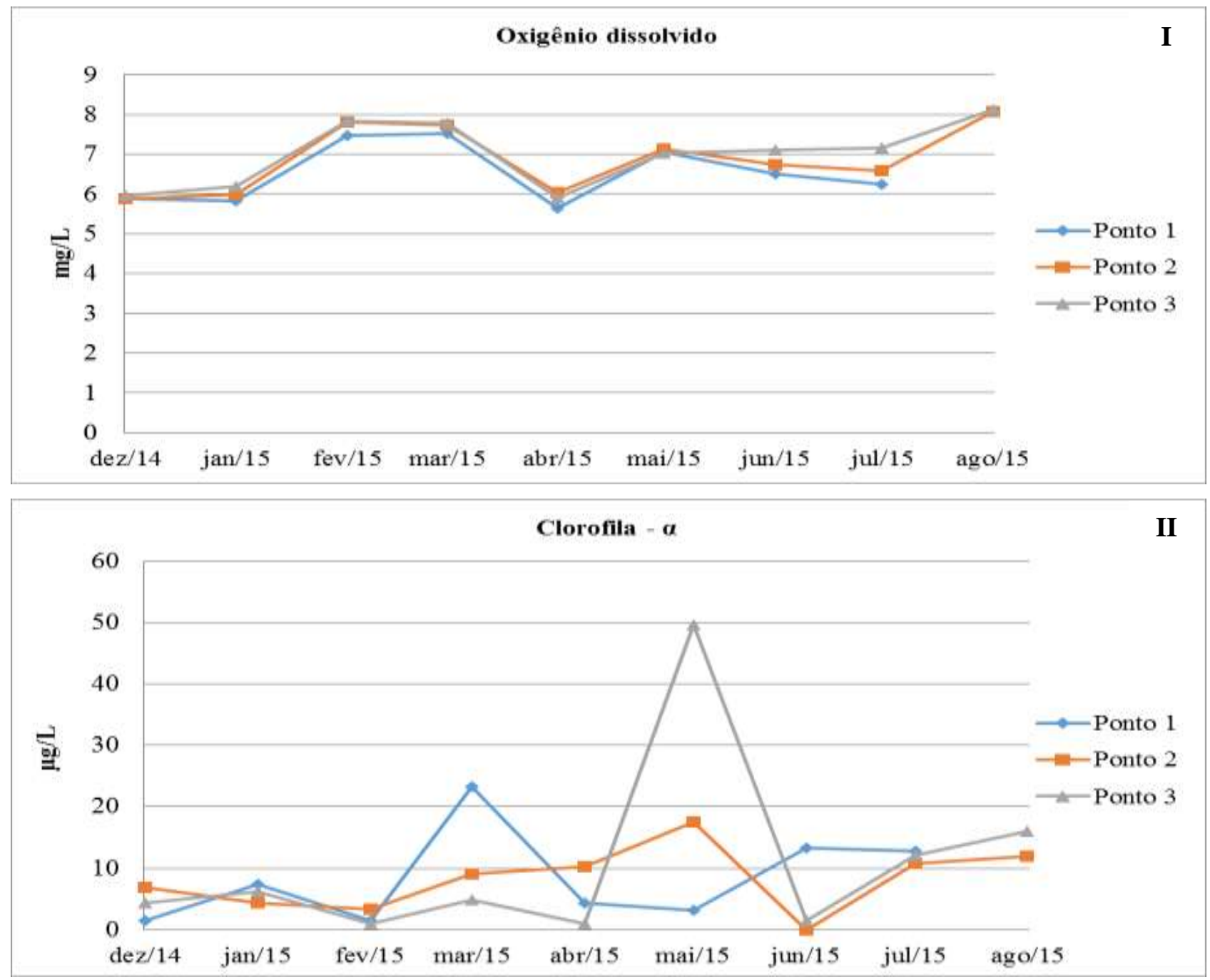

As variações dos nutrientes ortofosfato e nitrogênio (nitrito, nitrato e amônia) são apresentados na Figura 5. A disponibilidade de ortofosfato na Ipuca apresentou variação entre os três locais amostrais (Figura 5). Tais oscilações são frequentes devido a sua rápida incorporação pelas comunidades aquáticas [15]. A presença de fósforo na água possui origem natural na decomposição da matéria orgânica e na dissolução de compostos orgânicos no solo, sendo indispensável para o crescimento de algas, porém em altas concentrações pode causa a eutrofização do meio, pelo excesso no crescimento das plantas aquáticas [14]. Assim, valores de fósforo podem ser utilizados na detecção 
do grau de eutrofização de ambientes aquáticos. Sperling [13] afirma que maiores concentrações de fósforo podem ser aceitas em lagos tropicais não os tornando necessariamente eutrofizados. Assim, propôs uma faixa de detecção do grau de eutrofização em que valores de $\mathrm{P}<0.01-0.02 \mathrm{mg} / \mathrm{L}$ : são indicativos de local não eutrófico; valores de $\mathrm{P}$ entre 0.01-0.02 e 0.05 mg/L indicam um estágio intermediário de eutrofização; e valores de $\mathrm{P}>0.05$ $\mathrm{mg} / \mathrm{L}$ indicam local eutrófico. Considerando estes valores propostos, para a Ipuca estudada, o Ponto 2 está num estado intermediário de eutrofização. Já para os Pontos 1 e 3 se apresentam em estado não eutrófico (Figura 5).

O nitrogênio pode se apresentar na água em várias formas: nitrato $\left(\mathrm{NO}_{3}\right)$, nitrito $\left(\mathrm{NO}_{2}\right)$, amônia $\left(\mathrm{NH}_{3}\right)$, íon amônio $\left(\mathrm{NH}_{4}\right)$, óxido nitroso $\left(\mathrm{N}_{2} \mathrm{O}\right)$, nitrogênio molecular $\left(\mathrm{N}_{2}\right)$ e pode ser aderido ao ecossistema aquático através da chuva, material inorgânico de origem alóctone e a fixação do nitrogênio no próprio lago. Altos valores de nitrogênio no meio, assim como o fósforo, podem conduzir o ambiente aquático a um estado estrófico $[14,16]$. Os valores de amônia $\left(\mathrm{NH}_{3}\right)$ apresentaram o mesmo comportamento entre os três locais amostrados no decorrer do tempo, com pico em fevereiro, e queda nos meses seguintes, apresentando-se elevados no último mês de monitoramento (Figura 5). Esteves [15] afirma que em reservatórios formados sobre floresta é comum uma elevada taxa de amônio no período de seca, pois a decomposição da biomassa vegetal sedimentada acumula nitrato, nitrito e nitrogênio amoniacal na parte inferior a coluna d'água.

O processo de transformação do nitrogênio no ciclo bioquímico, conversão de amônia a nitrito, e deste a nitrato, consome grande quantidade de oxigênio dissolvido [14]. Assim, para oxidar um miligrama de íon amônio são necessários 4,3 miligramas de oxigênio, por isso, a presença do íon amônio em grandes concentrações pode causar uma perda na quantidade de oxigênio [15]. Os valores de nitrito $\left(\mathrm{NO}_{2}\right)$ mostraram-se oscilantes durante todo o período de amostral (Figura 5). No entanto, os valores foram menores que os valores de amônia e nitrato, característica típica de ambientes lênticos [15].

Os valores de nitrato, que entre dezembro e maio, mostraram comportamento similar entre os pontos amostrais, variaram nos três meses finais do período amostral (Figura 5). Em junho, foi observado um pico no Ponto 1 e queda no mês seguinte. No Ponto 2 manteve-se estável até agosto, quando houve um aumento significativo. No Ponto 3 manteve-se constante durante todo o período amostrado. Essa variação provavelmente acorreu porque a distribuição de nitrato em ambientes lênticos de regiões tropicais é influenciada pela ação de bactérias nitrificantes e desnitrificantes, que trabalham em conjunto na lamina d'água [16].

Figura 5: Variação da concentração de Ortofosfato (I), Amônia - $\mathrm{NH}_{3}$ (II), Nitrito - $\mathrm{NO}_{2}$ (III) e Nitrato $\mathrm{NO}_{3}$ (IV) nos três locais amostrais no decorrer do período amostral.

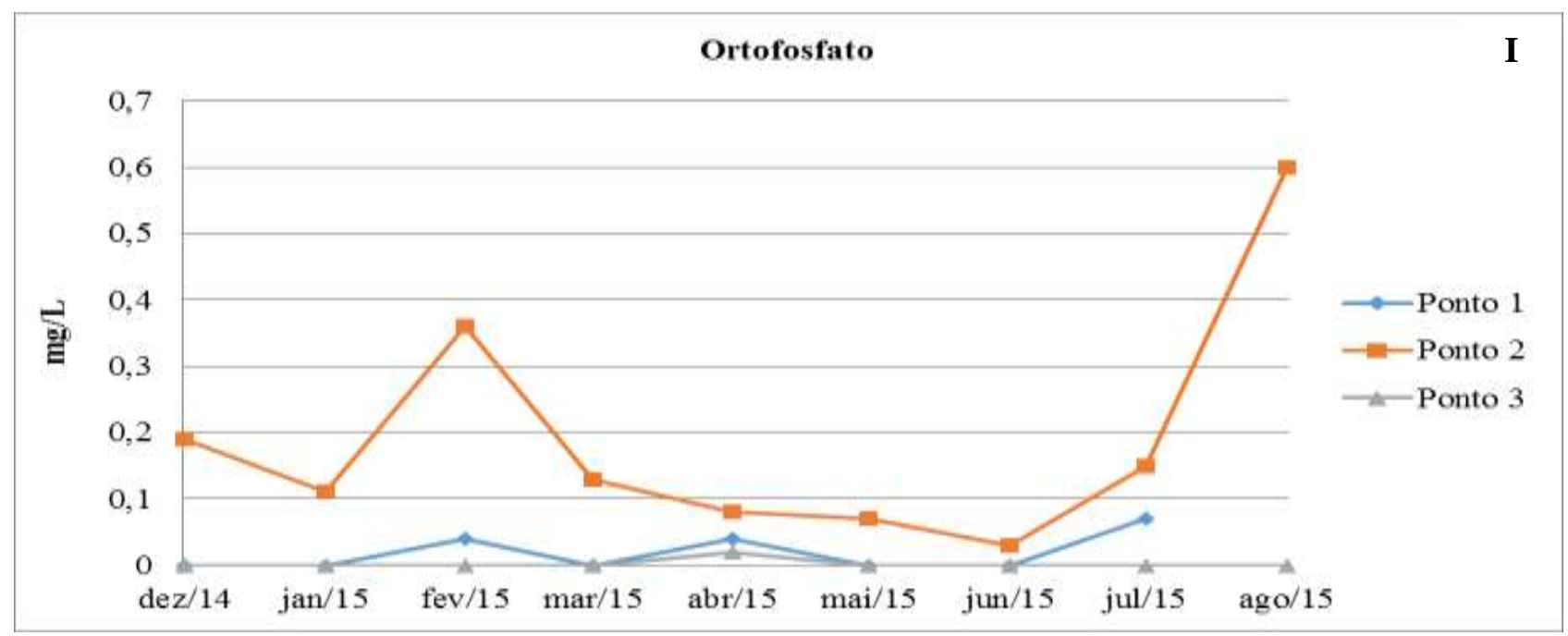



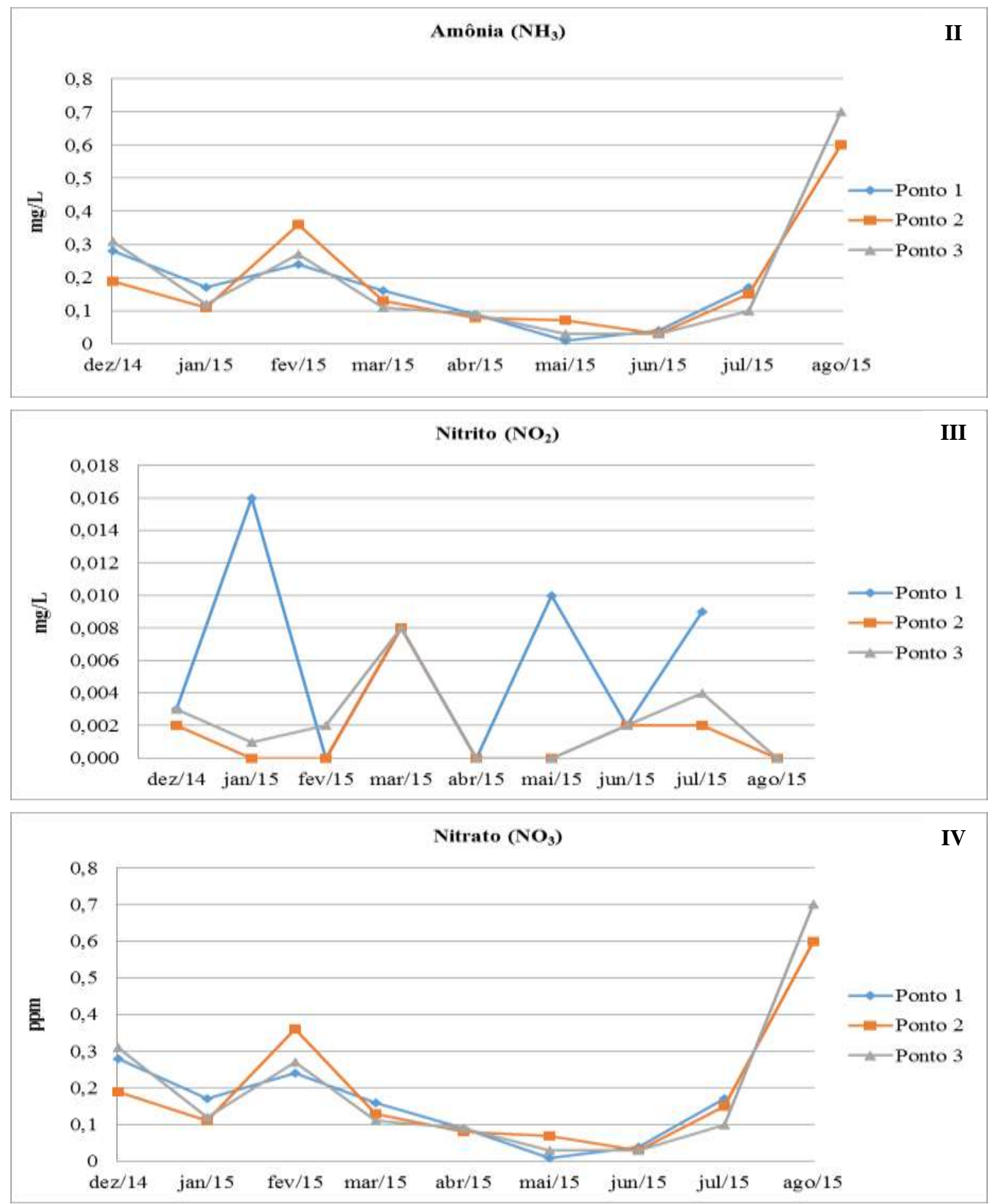

\section{AGRADECIMENTOS}

Ao Laboratório de Microbiologia e Biotecnologia Ambiental, anexo II (águas), pela estrutura oferecida para realização da analises físicoquímicas e à Capes pelos auxílios financeiros.

\section{CONTRIBUIÇÃO DOS AUTORES}

1. Condução e avaliação do experimento:

Hiulha de Jesus Silva

Marcus Vinicius Moreira Barbosa

2. Planejamento, orientação e revisão final do artigo Dr ${ }^{\mathrm{a}}$. Paula Benevides de Morais 


\section{REFERÊNCIAS}

[1]. MARTINS, A. K. E.; SCHAEFER, C. E. G. R.; Silva, E.; SOARES, V. P.; CORRÊIA, G. R.; MENDONÇA, B. A. F. Relação solo-geoambiente em áreas de ocorrência de Ipucas na Planície do MédioAraguaia - Estado do Tocantins. Revista Árvore, v. 30, n. 2, p. 297-310, 2006.

[2]. BRITO, C. F. P. de; MARTINS I. C. M. de; MARTINS, A. K. E. Avaliação multitemporal da regeneração dos fragmentos florestais naturais ipucas, Lagoa da Confusão-TO. In: SIMPÓSIO BRASILEIRO DE SENSOREAMENTO REMOTO, 13., 2007, Florianópolis. Anais... INPE, São José dos Campos, 2007. p. 2365-2372.

[3]. HAIDAR, R. F.; DIAS, R. R.; PINTO, J. R. R. Projeto de Desenvolvimento Regional Sustentável. Mapeamento das Regiões Fitoecológicas e Inventário Florestal do Estado do Tocantins. Regiões Fitoecológicas da Faixa Norte. Escala 1:100.000; Palmas: Seplan/DZE, 2013. v. I, p. 84-85.

[4]. MMA- Ministério do Meio Ambiente. Caderno da Região Hidrográfica do TocantinsAraguaia/Ministério do Meio Ambiente, Secretaria de Recursos Hídricos. - Brasília: MMA, 2006. p. 21.

[5]. VIEIRA, D.J. E.; NUNES, G. M.; SILVA, T. S. F.; ITALO, L. C. L. Análise da mudança da cobertura da terra na região do Parque Estadual do Araguaia, MT, por meio de classificação orientada a objeto e dados Landsat 5 TM. In: SIMPÓSIO BRASILEIRO DE SENSOREAMENTO REMOTO, 16., 2013, Foz do Iguaçu. Anais... Mato Grosso: UFMT, Faculdade de Engenharia Florestal, Laboratório de Sensoriamento Remoto e Geotecnologias. INPE, Instituto Nacional de Pesquisas Espaciais. INAU, Instituto Nacional de Ciência e Tecnologia em Áreas Úmidas, 2013. p. 71927199.

[6]. PIEDADE, M. T. F.; SCHOENGART, J.; JUNK, W. J. O Manejo Sustentável das Áreas Alagáveis da Amazônia Central e as Comunidades de Herbáceas Aquáticas. Revista Uakari, v. 1, n. 1, p. 29-38, 2005.

[7]. GUIMARÃES, W. L.; NOLL, M. S. M. C.; ARAÚJO, A. S.; PATERNINA, M. O.; STEPHAN, L. R. A influência do pulso de inundação sobre as variáveis limnológicas em lagoas marginais. In: SEMANA DA BIOLOGIA, 30 a Edição. Instituto de Biociências, Letras e Ciências Exatas - UNESP, Campus de São José do Rio Preto. 2014

[8]. DARWICH, A. J.; APRILE, F. M.; ROBERTSON, B. A. Variáveis limnológicas: contribuição ao estudo espaço-temporal de águas pretas amazônicas. In: SANTOS-SILVA, E. N.; APRILE, F.M.; SCUDELLER, V. V.; MELO, S. (Ed). Meio Físico, Diversidade Biológica e Sociocultural do Baixo Rio Negro, Amazônia Central; Manaus: Instituto Nacional de Pesquisas da Amazônia, 2005, p. 21-34.

[9]. PEREIRA, M. B.; BLEICH, M. B. P. Variação limnológica abiótica espacial e temporária em uma lagoa na bacia Araguaia-Tocantins, Mato Grosso. Cessumar, v. 11, n. 1, p. 29-35, 2009.

[10]. FERREIRA, A. B.; PEREIRA FILHO, W.; ROSA, R. Análise comparativa de variáveis limnológicas em três sub-bacias hidrográficas da região central do Rio Grande do Sul-Brasil. Revista on line Caminhos de Geografia, v. 13, n. 41, p. 15-28, 2012.

[11]. AMERICAN PUBLIC HEALTH ASSOCIATION (APHA). Standard Methods for the Examination of Water and Wastewater. 21. ed. Washington: APHA/WEF/AWWA, 2005.

[12]. INMET-Instituto Nacional de Meteorologia. Estações automáticas - Estação meteorológica de observação de superfície automática. Disponível em: < http://www.inmet.gov.br/portal/index.php?r=estacoes/est acoesAutomaticas>. Acesso em: 25 agosto 2015.

[13]. SPERLING, M. V. Introdução à qualidade das águas e ao tratamento de esgoto. Belo Horizonte: Departamento de Engenharia Sanitária e Ambiental; Universidade Federal de Minas, 2005. p. 445.

[14]. BREUNIG, F. M.; WACHHOLZ, F.; PEREIRA FILHO, P.; PRADO, B. R. Caracterização limnológica do reservatório Rodolfo Costa e Silva - ITAARA/RSBrasil. Revista Geográfica Acadêmica, v. 5, n. 1, p. 8597, 2011.

[15]. ESTEVES, F. A. Fundamentos de Limnologia. Rio de janeiro: Interciência, 2011. p. 826.

[16]. OLIVEIRA, L. C. de; GOMES, B. M.; BAUMGARTNER, G.; SEBASTIEN, N. Y. Variação espacial e temporal dos fatores limnológicos em riachos da microbacia do Rio São Francisco Verdadeiro. Jaboticabal, Engenharia Agrícola, v. 28, n. 4, p. 770$781,2008$. 